The Extent to Which First Year Humanities Students Read for Leisure 


\title{
A Study of the Extent to Which First Year Humanities Students at the University of Botswana Read for Leisure
}

\author{
Lone E. Ketsitlile and Golebamang Galegane \\ Communication and Study Skills Unit, University of Botswana \\ Ketsitlilele@Mopipi.Ub.Bw,Golebaof@Gmail.Com \\ Communication and Study Skills Unit, University of Botswana \\ Galegane@Mopipi.Ub.Bw
}

\begin{abstract}
In this paper, we discuss the extent to which selected first year students from the Faculty of Humanities at the University of Botswana read for leisure. From the interviews, questionnaires and observations, students in the Faculty of Humanities do very little reading for leisure. Reading for leisure needs to be encouraged among university students in general as it encourages the acquisition of knowledge and it is also a form of relaxation.
\end{abstract}

\section{INTRODUCTION}

Most research studies on the issue of leisure reading in Africa have focused on secondary school reading and problems that hinder leisure reading. A survey carried out in libraries revealed this to be true. Sampa (2003) reports a very low culture of reading in Zambia. Very few people are visiting libraries and people generally need to read to pass examinations. Sampa is of the view that, although people are able to read road signs and make budgets in their homes, more is blamed among others for poor reading levels.

In Botswana, a study carried out by Arua \& Lederer (2003) reveals that the purpose of reading is for academic purposes. $78 \%$ of the students in the sample read to pass their examinations and gain general knowledge. Only $18 \%$ of the students surveyed read for leisure. Materials that are difficult resulted in many students not liking books (p. 27). From personal observation as University of Botswana (U.B.) lecturers, we were surprised by the culture of reading at UB. Students are not always reading something for leisure between lessons, at the halls of residence or online. The majority of what they read is for academic purposes. This study is the first of its kind at the University of Botswana.

The study will inform researchers, reading specialists and governments about students reading for leisure activities and what needs to be done to 
improve reading as a culture among undergraduate students. In the study we explored reading for leisure habits of undergraduate students at the UB to find out the extent of their reading for leisure, their experiences and what it means for them. Investigating this problem will help them improve in the areas of language and overall achievement at university. Students who come from secondary school have poor English language skills hence, the need to investigate the problem (Chimbganda 2003). The problem of not readingfor leisure is not peculiar to Botswana: it is a global issue (Kibby, 1993).

Hughes-Hassell \& Rodge (2007) have studied leisure reading among students at high school in the USA. Their findings were specifically on leisure reading habits. In another study in the USA, Brozo, Shiel \& Topping (2008) in their study highlighted that students should be involved in leisure reading daily. As governments in Africa attempt to better the lives of their people through improved health, nutrition, education and other programs the issue of ensuring that people do read and retain the habit of reading throughout their lives, cannot be ignored. A culture of reading is also important for a number of reasons:

a. Reading of any kind increases knowledge and takes the reader to other lands, cultures and countries.

b. $\quad$ Reading liberates individuals

c. Reading for leisure is a form of play

\section{Background to the study}

Culturally, Africans are not known for their culture of reading (Molosiwa, 2007). Reading for leisure or pleasure is still considered very much a western practice. African people believe in telling stories and this is a preferred mode of sharing knowledge with others. An unknown author once said that if one needs to hide anything from an African, they should put it in a book. African students generally read for academic purposes and to pass examinations (Arua \& Lederer, 2003).

Hargeisa, from Somalia is of the view that reading for leisure is very rare in Africa (BBC News Africa, 27 $7^{\text {th }}$ October, 2005). According to Tumusiime (2003), the absence of a reading culture in African societies has been the concern of many. He goes on to say African governments have spent millions of dollars in buying books, paying teacher's salaries and funding libraries but still there is no reading culture. Simply put, reading for leisure is not a habit in Africa, including Botswana. According to research, Africans traditionally rely on stories to pass on information, for entertainment and for new information (Ketsitlile, 2009; Molosiwa, 2007; Shostak, 2000).

\section{Research questions}

Our study is guided by the following research questions:

1. What does reading for leisure mean to the undergraduate students at the University of Botswana? 
2. How do UB undergraduate students perceive the role (s) of leisure reading in their lives?

3. What barriers exist in the students' endeavor to read for leisure?

\section{Review of the literature}

\section{What is reading for leisure?}

Leisure reading is a form of play. It is an action taken outside the normal life activities and one engages in it for ease or relaxation. Mellon (1990) as cited by Hughes-Hassell \& Rodge (2007) states that reading for leisure is the reading that students choose to do on their own, as opposed to reading that is assigned to them. In view of the above, this study aims to find out if undergraduate students at the University of Botswana are engaged in this 'play' and if they have a time and place for reading on their own in their lives. Research points to the fact that reading for leisure is a habit that is encouraged and taught (Bamhere, 2003).

\section{Advantages of reading for leisure}

Leisure reading is an important component in reading for academic purposes. Research has indicated a strong relationship between leisure reading and school achievement (Hughes-Hassell \& Rodge 2007). Researchers who have explored reading and mentoring encourage teachers to build and maintain supportive, caring relationships with students and engaging activities that communicate to students that leisure reading is an important component of their academic work and personal lives (Pianta, Stuhlman \& Hambre, 2002). Students at all levels should be encouraged to read a lot as this prepares students to be life-long readers. Being life-long readers is spiced by motivation, improved vocabulary and comprehension skills (Brozo, Shiel \& Topping, 2008; Friedland \& Truscott 2005; Pitcher et al, 2007). Life-long reading also encourages critical thinking skills. Research has documented the benefits of wide reading habits. Makenzi (2003) says that reading is one of the most rewarding pursuits in life and "an art that is central to human development. Through reading, individuals develop insights of a world beyond the life that they actually live." (p. 36). Another advantage of reading for leisure is that it builds on an oral language competence (Koda, 2007). Koda is of the view that having this competence will help build ones confidence.

\section{Materials for leisure}

Magazines ad newspapers are commonly read for leisure (Hughes-Hassell \& Rodge, 2007). In Botswana, a study carried out by Arua \& Lederer (2003) reveals that those students who read for leisure preferred English novels to American or African. Kgafela \& Biakolo (1998) also observed the same 
behaviour. Arua \& Lederer (2003) stated that few Africans write novels for leisure. They observed that few African novels are regarded as class texts to be read for examinations rather than for leisure. The texts tend to be produced for school use (p.27). From their responses, Botswana secondary school students also revealed that they read foreign magazines much more than the local ones. This might be because there are few local magazines published in Botswana. Most magazines are from the United States and South Africa.

\section{Leisure reading habits}

Leisure reading done outside school relates to achievement in vocabulary, reading comprehension, verbal fluency and content knowledge (HughesHassell \& Rodge, 2007; Brozo et al, 2008). Reading materials take a variety of forms including continuous texts such as narration, exposition and argumentation. There are also non-continuous texts that are included such as graphs, forms and lists (Brozo et al, 2008). Many African children do not grow up surrounded by books. Most children have seen their parents or guardians read only the Bible and in some case, the local newspaper (Molosiwa, 2007). This is because traditionally, African peoples learn a lot through the word of mouth. The culture is very much oral: stories are told from one generation to another through the word of mouth. For example, when a chief of an ethnic group announces a meeting at the kgotla (traditional meeting place), no leaflets or memorandums are sent out to announce the meeting. Instead, the chief's messengers or the media will inform people about the meeting. The same is true for social events like a birth of a child or a death in the family (Molosiwa, 2007).

\section{Problems or barriers of leisure reading}

The problems that hinder leisure reading are numerous. One of them is lack of motivation by students. Motivation is an important behaviour for reading and its absence will lead to negative impact on the students' achievement (Elley, 1995; Hughes-Hassell \& Rodge, 2007; Kgafela and Biakolo, 1998). Lack of adequate techniques to teach reading skills, unavailability of books and training of teachers and librarians on the need for leisure reading needs to be encouraged.

\section{Research Design}

The qualitative method is appropriate for this study. This type of research design provides an in-depth understanding of human behavior by investigating the "how" and "why" of decision making. According to Johnson-Bailey (2007), there are a number of characteristics of qualitative research design: i) it attempts to understand the whole picture of the social context not just a particular segment, ii) it looks at relationships within a system or subculture iii) refers to the personal, face-to-face immediate 
interactions in a given setting, iv) reality is constructed by the individual interaction with the social world, v) it is a primary inductive process whereby variables are not manipulated nor predicted but instead the researcher focuses on understanding the social setting of the participants and vi) it includes a number of different methods which provides a detailed description of the data and enables triangulation. Although qualitative research demands equal time in the field and in analysis it is also much richer. It also provides a flexible schedule for the researcher by incorporating complete descriptions of the role of the researcher. Using qualitative research in this study enabled us to gather detailed and precise information about the phenomenon. Qualitative research highlights the experiences of the undergraduate students. Chilisa and Preece (2005) state "qualitative research refers to the type of inquiry in which the researcher carries out research about people's experiences, in natural settings, using a variety of techniques such as interviews and observations, and reports findings mainly in words rather than statistics" (p. 142). They go on further to say that some of the characteristic of qualitative research emerge from the way the research problem and research questions are conceived, the steps in designing the study and the analysis (p. 142).

\section{Theoretical Framework}

This study is informed by the interpretive framework. The interpretive framework can be traced back to Edmund Husserl's philosophy of phenomenology and the German philosopher Wilhem Dilthey's philosophy of hermeneutics (Eichelberger, 1989: Neuman, 1997). The key construst in Husserl's framework of phenomenology is intentionality, that is, time is a key element. It is what the individual readerintends to do with what he or she reads that is important. According to Chilisa \& Preece (2005), interpretivists believe that knowledge is subjective and socially constructed, unlike the positivists/post-positivists who believes in the objectivity of knowledge.

It is not common, cultural or a habit for undergraduate students to read for leisure. Since another tenet of the interpretive/phenomenological framework is the notion of 'beliefs' or 'habits', we found phenomenology to be relevant. In finding out these 'beliefs' or 'habits', we feel it is appropriate for the voice of the undergraduate students to be heard because from the phenomenological perspective, truth lies within the human experience and is three-fold: it is time and space. While it is important for researchers to give a critical view of leisure reading among graduate students, we feel it is equally important for researchers to document the voice of the undergraduate students to see how they perceive leisure reading.

\section{Sample selection and procedure}

The research was carried out among UB undergraduate students of the Faculty of Humanities. We decided on the Faculty of Humanities because it was more convenient for both of us as we are offering Communication and 
Study Skills to first-year students in the Faculty of Humanities. Students were given questionnaires to complete during lecture periods in order to find out about their leisure reading habits.

We employed purposeful sampling. We chose among those participants who we thought could give us rich lived experiences and be willing to share their stories. The number of the participants for the study is 72 out of about 360 students taking Communication and Study Skills in the Faculty of Humanities. We feel this is representative of the population of Faculty of Humanities undergraduate students at the University of Botswana as it was spread across all first-years students.

\section{Subjects}

There were 31 males and 41 females in the study. Their age range was between 18 and 28. 25 of the subjects reside on campus and 47 off campus. The common languages spoken are English and Setswana with only 2 students speaking only English and 12 speaking a third language (Afrikaans, French, Kalanga, Shona, Herero and Ndebele). Ten students from each of the nine groups were given a questionnaire, but only 72 questionnaires were completed.

To collect data for this study, the Communication and Study Skills six lecturers teaching Humanities first-year students were given 10 questionnaires for each class. They were to give 5 to males and 5 to females who could provide information. The main questions in the questionnaire were the materials that that the students read for leisure, leisure reading habits and encouragement for reading. The questions were on a four and a five point Likert Scale. There were also three open-ended items.

\section{DATA COLLECTION METHODS}

As researchers, we seek to understand rather than formulate a scientific explanation. We used phenomenological approach of giving the research subjects a questionnaire. The phenomenological approach uses interviews and observations as the primary methods of data collection. This method of inquiry uses various techniques to determine the particular experience of the individuals being studied. Using a phenomenological form of inquiry enabled the researchers to understand in detail the undergraduate experience. We employed member check after the observations, questionnaires and interviews in order to seek for clarification from the participants.

We focused mainly on the semi-structured interview data. We interviewed all the 10 students using semi-structured interview protocol, in order to allow the researchers to maximize their information. Marshall \& Rossman (2006) described ethnographic interviewing as an elaborate system of a series of interviews structured to elicit insider's cultural knowledge. Using both phenomenological and ethnographic framework in this study 
helped us to gain rich, detailed and contextual information about the life and cultural experiences of these students.

Observation is important in qualitative research. We carried observations over a period of a month with six selected students (three females and three males). We observed students in their rooms at different times during the day and we noted the reading for leisure materials that they had. In participant observation, the researcher is very much part of the setting (De Walt, 2002). We concur with Emerson et al (1995), that participant observation leads to an informed understanding of the lived experience more, as the researcher is present. He/she can follow hunches on site more closely than any other method and this can lead to asking leading questions of the lived experiences. The presence of the researcher in qualitative study is crucial to the success of the study. The relevant data will be categorized into:

$$
\text { Perceptions on pleasure/leisure reading }
$$
Pleasure/leisure activities (if any)

From the observations, students generally read South African newspapers for leisure. The popular ones are Drum and True Love. The Botswana newspaper that students liked to read is The Voice.

Questionnaires: The questionnaire was employed in the present study to triangualte the data. The questionnaire was also employed to collect data from a wider sample than is the case in the interview and observations (Patton, 2001).

\section{Ensuring validity and reliability}

The concept of validity has been described in a wide range of terms in qualitative studies. For this study, validity will be employed to explain or measure what this research seeks to find. To ensure validity, there are strategies we adopted to provide credible findings. First, we conducted the interviews and made observations. Secondly, we conducted informal member checks with the informants to check on data we may not be sure of. In doing so, words and scenarios that were misunderstood were clarified and more details obtained. Thirdly, we used peer examination to ensure we have plausible findings by consulting with some colleagues, to obtain their views about the research study that is triangulation.

Patton (2001) suggests that reliability addresses how accurate research methods and techniques produce data to ensure that one's' data is triangulated. It is very important to establish trustworthiness with the readership by adequately describing the findings and how we arrived at them. Additionally, we made sure we informed our readers our assumptions, biases and subjectivity related to this study.

We ensured reliability by data triangulation in the following ways:

Methodological triangulation: We will compare the data from the interviews, observations and questionnaire. 

and place of my observations Theoretical triangulation: We will compare the ideas and experiences from males and females.

\section{Limitations of the study}

It would have been beneficial to have carried out the study across faculties at the University of Botswana. However, due to lack of funding, we limited our study to only the Faculty of Humanities. It was most convenient for us to observe those students who stay on campus as some students stay as far as 85 kilometers. We did not receive all the expected feedback as some questionnaires were not returned to us.

\section{Data analysis}

The data was analyzed in the following manner:

1. Questionnaires: The questionnaire was designed in four folds. The first part focused on the biographic information. The second on "The materials read for leisure". The third and the fourth covered "The Reading Habits" and "Encouragement for leisure reading" respectively. The questinnaire consisted more of close-ended items than open ended items. These were coded and analysed.

2. Interviews: The interviews were transcribed. According to Charmaz (2006) a transcription is a written representation of the interview. We were mainly interested in what the students communicated during the interview. We then coded the data and came up with concepts and categories after looking at the data line by line. This helped us in being intimate with our data and hence, assisted in coming up with identified recurring themes from the coded data. The data was categorized into the following main themes:

$\begin{array}{ll}-\quad & \text { Leisure reading materials } \\ -\quad & \text { Reading habits } \\ -\quad & \text { Leisure reading times }\end{array}$

3. Observations: Detailed notes were made from the setting. From these notes, we came up with common themes and categorized them into groups. The groups were them named according to:

- Materials and artifacts found in the students rooms

- Materials and artifacts the students were engaged in during observation periods. 


\section{RESULTS AND DISCUSSION}

\section{Presentation of results}

Seventy-two (72) students responded to the questionnaire.

\begin{tabular}{ll}
\hline Table 1: Personal data. & \\
\hline Age (years) & Number of students \\
\hline $18-21$ & 57 \\
$22-24$ & 5 \\
$25-27$ & 3 \\
28 and above & 7 \\
Total & $\mathbf{7 2}$ \\
\hline
\end{tabular}

Most of the students who responded to the questionnaire are between 18 and 21 years of age. This is not surprising as these students are new to the University and have just completed their secondary schooling.

Table 2: Gender.

\begin{tabular}{ll}
\hline Female & Male \\
\hline 41 & 31 \\
Total & $\mathbf{7 2}$ \\
\hline
\end{tabular}

We felt gender is important in the study for cross tabulations. We wanted to find out who read for leisure more: female or male. This we deemed important as research continually points to the fact that females are engaged in more leisure reading than their male counterparts (57\%). From the findings of the questionnaire results, females read more for leisure. Male students preferred to read newspapers.

Table 3: Residence.

On Campus 25

Off Campus 25

Total 
Table 4: Humanities.

Environmental Science and English

Environmental Science and History

Library Studies

Sociology and English

Table 5: Languages spoken.

\begin{tabular}{lr} 
Languages and Setswana & 58 \\
English & 2 \\
Others & 12 \\
(Afrikaans, French, Kalanga, Shona, Herero, Ndebele) & $\mathbf{7 2}$ \\
\hline
\end{tabular}

English and Setswana are the two official languages in Botswana. There are about 23 minority languages in Botswana, but according to Batibo and Smieja (2000), it is difficult to determine the exact number of minority languages in Botswana because most minority languages, particularly the Khoesan ones, form language clusters involving several linguistic or sociocultural entities. The policy supports minority language instruction but in practice, this is not the case. According to Nyati-Ramahobo (1991, p. 201) " the language planning processes in Botswana are influenced by an orientation which views language diversity as a problem, a reversal or negation of democratic gains, a threat to unity, social harmony and to development."

According to Nyati-Ramahobo (2004) the Botswana Government opposes the use of minority languages in government, education, politics and business under the guise of national unity, to the advantage of Setswana which is marketed as a unifying language in

Botswana. We concur with Mooko (2006) that this 'unity' disregards the importance of cultural diversity in Botswana. As a result of ignoring mother tongue instruction in schools, English and Setswana are in most cases second and third languages for minority children in Botswana (Monaka \& Chebanne, 2005). The Revised National Policy of Education (RNPE, 1994) reversed the decisions of The National Council of Education (NCE , 1993) and recommended that Setswana be used for instruction in the first three years of a child's schooling and English be taught from standard 3. 
Table 6: Materials read for leisure.

\begin{tabular}{lr}
\hline Newspapers & 16 \\
Novels & 13 \\
Magazines & 9 \\
Newspapers and magazines & 10 \\
Novels and magazines & 3 \\
Newspapers and textbooks & 1 \\
Magazines and textbooks & 1 \\
Newspapers and novels & 1 \\
Newspapers, magazines and novels & 14 \\
Newspapers, magazines and textbooks & 2 \\
Textbooks for school & 1 \\
I never read & 1 \\
Total & $\mathbf{7 2}$
\end{tabular}

From what is read it came out clearly that the majority of students liked reading about celebrities $(33.3 \%)$ and liked to read about historical figures $(25 \%)$. Only (4.2\%) students indicated that they liked to read about animals. About $5 \%$ of the students indicated that they read 'other' materials. Generally, there is very little reading of newspapers, magazines and novels byfor leisure undergraduate humanities $(19 \%)$ students at the University of Botswana during the school term or during the school holidays. However, some students did engage in some leisure reading.

Less than $50 \%$ of the students read for leisure on a daily basis. Only $12 \%$ of the students read leisure materials fortnightly and $48 \%$ weekly. $5 \%$ of the students never read for leisure. Only $40 \%$ of the students indicated that they liked reading for leisure very much and 30\% liked to read sometimes. No student opposed reading for leisure.

Table 7: Use of internet for leisure reading.

\begin{tabular}{lc}
\hline Once a week & 23 \\
Twice a week & 32 \\
Daily & 17 \\
Not at all & 0 \\
Total & $\mathbf{7 2}$ \\
\hline
\end{tabular}

23 students out of $72(32 \%)$ stated that they read online once a week while 32 (44\%) read twice a week. Only 17 (24\%) students read online daily. This limited reading online is that computers are not enough for all students. We project that the numbers reading online will grow steadily as there is wireless connection in the university. 
Table 8: Sources of materials.

Buy

Rent

Library

Buy and Library

Never read for leisure
30

1

29

11

Total

From the study, it is clear that there is some reading for leisure amongst first year students in the Faculty of Humanities (print and online). However, from the study, problems exist in the reading for leisure at the University of Botswana. This might be because there are very few local magazines from Botswana and most magazines are from the US and South Africa. The students found foreign newspapers to be very expensive and hence, read local newspapers. In addition, reading for leisure is not part of Botswana and African culture in general.

\section{RECOMMENDATIONS}

- $\quad$ The reading for leisure by students needs to be encouraged from primary school so that they can take delight in reading.

- University lecturers should encourage students to read outside academic reading..

- Botswana newspapers should be made much more accessible for university students and newspaper stalls should be erected at focal point, for example, the refectory, bus stop and outside the bookstores.

- $\quad$ More computers should be provided in the university to encourage online reading.

\section{CONCLUSION}

Reading for leisure is not a habit for undergraduate humanities students at the University of Botswana. Students prefer to read for tests and assignments than to read for leisure. Clearly, reading for leisure is not among their top priorities. Hence, students need to be sensitized at an early age on the advantages of reading for leisure by teachers and parents. In addition, leisure reading materials should be easily available and accessible to students and should be affordable too. Leisure reading materials need to be interesting to students as well. 


\section{REFERENCES}

Arua, E.A. and Lederer, M. (2003). What are students in Botswana High Schools reading? In A. Arua (Ed.), Reading for all in Africa. (pp. 26-31) Newark, DE: International Reading Association.

Bamhare, M, (2003). Mobilizing local resources for reading promotion. In A. Arua (Ed.), Reading for all in Africa. (pp. 23-29). Newark, DE: International reading Association.

Brozo, W.G., Shiel, G \& Topping, K. (2008). Engagement in reading: Lessons learned from three PISA countries. Journal of Adolescent \& Adult Literacy.

Chen, S. (2007). Extracurricular reading habits of college students in Taiwan: Findings from two national surveys. Journal of adolescent and adult literacy.

Chilisa, B. \& Preece, J. (2005). Research methods for adult educators in Africa. Cape Town: Pearson Education.

Friedland, E.S. \& Truscott, D.M. 2005. Building awareness and commitment of middle school students through literacy tutoring. Journal of Adolescent \& Adult Literacy.

Hargeisa, R.O. (2005). Reading for leisure in Somalia. BBC News Africa.

Hughes-Hassell, S \& Rodge, P (2007). The leisure reading habits of urban adolescents. Journal of Adolescent \& Adult Literacy. 51(1), 22-35.

Ketsitlile, L.E. (2009). San junior secondary school understandings of literacy in school and at home: A case study. Doctoral Dissertation. University of Georgia, USA.

Koda, K. (2007). Reading and Language Learning: Cross linguistic constraints on second language reading development. A Journal of Research in Language Studies.

Mackenzie, M. (2003). Developing and promoting lifetime reading habits in Kenya: The reading tent project and Njoro reading facility. In A. Arua (Ed.), Reading for all in Africa Newark, DE: International Reading Association.

Marshall, C. \& Rossman, G.B. (2006). Designing Qualitative Research. New York: Sage.

Mazonde, P. (2002). The San in Botswana and the issue of subjectivenessnational disintegration or cultural diversity? In Mazonde (Ed.), Minorities in the millennium: Perspectives from Botswana, (pp. 5771). Gaborone: Light books.

Meloy, J.M. (2002). Writing a qualitative dissertation: Understanding by doing. Mahwah, NJ: Lawrence Erlbaum Associates.

Merriam (1998). Qualitative research and case study applications in education. San Francisco: Jossey-Bass.

Molosiwa, A. (2007). Language and Literacy issues in Botswana. In PurcellGates (Ed.), Cultural practices of literacy in Education. Mahwah, New Jersey: Lawrence Erlbaum Associates, Inc. 
Moustakas, C. (1994). Phenomenological research methods. Thousand Oaks, CA: Sage.

Nell, V. (1988). The psychology of reading for pleasure: needs and gratifications. In Reading Research Quarterly, Vol. xxiii. No. 1, pp. 6-50.

Obanya, P. (2003). Towards a reading society. In (Ed.). Arua. Reading for all in Africa. (2-6). Newark, DE: International Reading Association.

Patton, M.Q. (2001). Qualitative evaluation and research methods $\left(3^{\text {rd }} \mathrm{Ed}\right)$. Thousand Oaks, CA: Sage Publications, Inc.

Pitcher, S.M; Albright, L.K; DeLaney, C.J; Walker, N.T; Seunarinesigh, K; Mogge, S; Headley, K.N; Ridgeway, V.G; Peck, S; Hunt, R \& Dunston, P.J. (2007). Assessing adolescents' motivation to read. Journal of Adolescent \& Adult Literacy. Sampa, F. (2003). Mother tongue literacy in the Zambian new breakthrough to literacy programme. In A. Arua (Ed.), Reading for all in Africa. (pp. 173178). Newark, DE: International Reading Association.

Shostak, M. (2000). Return to NISA. Cambridge: Harvard University Press. 